\title{
ИЗМЕНЧИВОСТЬ ПРОДУКЦИОННЫХ И МОРФОФУНКЦИОНАЛЬНЫХ ХАРАКТЕРИСТИК РАСТЕНИЙ ЖЕНЬШЕНЯ, КУЛЬТИВИРУЕМОГО В ПРИМОРЬЕ*
}

\author{
O.L. Burundukova, K.G. Khorosh
}

\section{THE VARIABILITY OF PRODUCTIVE AND MORPHOFUNCTIONAL CHARACTERISTICS OF CULTIVATED PANAX GINSENG IN PRIMORYE}

Бурундукова Ольга Леонидовна - канд. биол. наук, ст. науч. сотр. лаб. клеточной биологии и биологии развития ФНЦ биоразнообразия наземной биоты Восточной Азии ДВО РАН, г. Владивосток. E-mail: burundukova.olga@gmail.com Хорош Константин Григорьевич - старший инженер лаб. экотоксикологии популяций и сообществ Института экологии растений и животных, г. Екатеринбург. E-mail: khorosh_k@mail.ru

Дикорастущий женьшень Panax ginseng C.A. Mey. (Araliaceae) - редкое лекарственное растение. Цель исследования - оценка генетического разнообразия продукционных и морфофункциональных признаков растений женьшеня научно-производственной плантации. Задача исследования - изучение индивидуальной изменчивости и анализ корреляционной взаимосвязи веса корня и структурнофункциональных характеристик 60 растений шестилетнего культивируемого женьшеня. В анализируемой выборке обнаружено широкое варьирование растений: по весу корня - от 9,7 до 95,7 г (CV - 43 \%), числу семян - от 13 до 146 (CV - $48 \%$ ), по длине главного корня - от 1,5 до 15,0 cм (CV - $57 \%$ и и количеству боковых (от 1 до 10, CV - 42 \%) и придаточных (от о до 7, CV - 53 \%) корней. Существенно варьируют и параметры структуры биомассы, что отражает разнообразие типов донорноакцепторных отношений и морфотипов растений женьшеня на плантации. Более вариабелен индекс плодов CV - 37 \%, наиболее консервативен индекс корней CV - $10 \%$. Анализ корреляционной взаимосвязи веса корня и морфоофункциональных характеристик растений выявил достаточно высокую положительную связь с толщиной главного корня $(r=0,66$,
Burundukova Olga Leonidovna - Cand. Biol. Sci., Senior Staff Scientist, Lab. of Cellular Biology and Biology of Development, FRC of Biodiversity of Land Biota, Eastern Asia, FEB RAS, Vladivostok. E-mail: burundukova.olga@gmail.com

Khorosh Konstantin Grigoryevich - Senior Engineer, Lab of Ecotoxicology of Populations and Communities, Institute of Plant Ecology and Animals, Ekaterinburg. E-mail:khorosh_k@mail.ru

$p<0,05)$, числом боковых корней $(r=0,45$, $p<0,05)$ и площадью листьев на растении $(r=0,61, p<0,05)$. Высокая отрицательная корреляция веса корня наблюдалась с индексом листьев $(r=0,65 p<0,05)$. Представленное на плантации разнообразие генотипов по продуктивности, морфоотипу растений и морфологии корней свидетельствует о возможности проведения селекционных работ по созданию продуктивного приморского сорта женьшеня. По результатам наших исследований перспективными признаками для отбора могут быть - толщина главного корня, число боковых корней и площадь листьев растений женьшеня.

Ключевые слова: женьшень, продуктивность, изменчивость морфоологических признаков, морфотип, коррелящия.

Wild Panax ginseng C.A. Mey. (Araliaceae) is a rare medicinal plant. The purpose of the research was to assess genetic diversity of productive and morphofunctional characteristics of ginseng plants in scientific and industrial plantation. The research problem was studying individual variability and the analysis of correlation interrelation of root weight and structurally functional characteristics of 60 plants of ginseng cultivated for six-years. A wide

*Работа выполнена при финансовой поддержке гранта РФФИ 19-01600147. 
variation was found on root weight $(9.7-95.7 \mathrm{~g}, \mathrm{CV}$ - $43 \%)$, on seeds number (13-146, CV - $48 \%$ ), on the length of the main root - from 1,5 to 15,0 $\mathrm{cm}(\mathrm{CV}-57 \%)$ and to the quantity lateral (from 1 to $10, \mathrm{CV}-42 \%$ ) and subordinate clauses (from 0 to $7, \mathrm{CV}-53 \%$ ) roots. The parameters of the biomass structure also varied significantly, reflecting the diversity of donor-acceptor relations' types and morphotypes of ginseng plants on the plantation. The fruits index was more variable CV $-37 \%$ and root index was the most conservative CV - $10 \%$. The analysis of correlation interrelation of weight of the root and morphofunctional characteristics of plants revealed rather high positive communication with thickness of the main root $(r=0.66, p<0.05)$, the number of lateral roots $(r=0.45, p<0.05)$ and the area of the leaves on a plant $(r=0.61$, $p<0.05$ ). High negative correlation of root weight was observed with leaves index of $(r=0.65$, $p$ <0.05). The variety of genotypes presented on the plantation on the efficiency, the morphotype of plants and morphology of roots testified to the possibility of carrying out selection works on creation of a productive seaside variety of a ginseng. By the results of the researches perspective signs for selection can be the thickness of the main root, the number of lateral roots and the area of leaves of plants of ginseng.

Keywords: ginseng, productivity, variability of morphological characters, morphotype, correlation.

Введение. Женьшень - редкое лекарственное растение. Плантационное культивирование реликта призвано восполнить ресурсы ценного растительного сырья. В Китае и Корее женьшень культивируется в промышленных масштабах более 300 лет [1]. Результатом современной селекции женьшеня в Корее является выделение ряда разновидностей: Gumpoong, Sunpoong, Yunpoong, Sunone, Sunhyang, Cheongsun, - pasличающихся по цвету плодов, стеблей и листьев, биохимическому составу корней, продуктивности, устойчивости к патогенам [2]. Новейший сорт Kovon отличается высокой урожайностью и устойчивостью к биотическим и абиотическим стрессам [3]. Плантационное культивирование женьшеня на российском Дальнем Востоке длительный период переживало жесточайший кризис, вследствие этого совхоз «Женьшень» и многочисленные мелкие частные плантации, осно- ванные на посевном материале приморского происхождения, прекратили свое существование. В настоящий период плантации женьшеня возрождаются в различных районах Приморского края, но местные сорта, адаптированные к почвенно-климатическим условиям Приморья, отсутствуют.

Цель исследования: оценка генетического разнообразия продукционных и морфоофункциональных признаков растений научно-производственной плантации женьшеня для целей селекции.

Известно, что фоотосинтетические и морфофункциональные признаки имеют перспективу для селекции, если существует генетическое разнообразие по данному признаку и положительная корреляция с продуктивностью [4]. В задачу исследования входило изучение изменчивости веса и морфологических признаков корней, распределения биомассы по органам 60 растений шестилетнего культивируемого женьшеня и анализ корреляционной взаимосвязи продукционных и морфоофункциональных признаков.

Объекты и методы исследования. Объектами исследования были шестилетние растения женьшеня, культивируемые в условиях научнопроизводственной плантации, расположенной в окрестностях г. Дальнегорска (Приморский край). Культивирование женьшеня осуществляли в соответствии с рекомендациями, приведенными в работах $[5,6]$. Использован посадочный материал приморского происхождения - семена закупали в совхозе «Женьшень» и частных плантациях Приморского края. Для затенения растений использовали высокие (2 м) сооружения (шеды) из досок с просветами 2-3 см, обеспечивающие боковую и горизонтальную защиту от солнечных лучей и ветра. Затенение обеспечивало пропускание 15-25 \% солнечного света. Высота гряд составляла 25-30 см, ширина - 1 м, междурядья 60 см. Для посадки в грунт использованы саженцы 2-летнего возраста, выращенные из семян, прошедших стратификацию в зимний период. Грунт был подготовлен из смеси перегнойного верхнего слоя лесной подстилки, торфа и песка в сочетании $1: 1: 1$ с добавлением азотно-фоссфорнокалийных удобрений, аммиачной селитры. Под- 
готовка производилась в грунтовых буртах высотой 1,5 м в течение 1-2 лет с перемешиванием каждый месяц в теплый период года. Кислотность доводилась до 6,5 рН доломитовой мукой. Проводились полив равномерный без значительного высыхания гряд, рыхление поверхности почвы, уборка всех сорняков. Регулярно проводились профилактические мероприятия против патогенов. Для защиты от поражения в период стратификации ффзариозом (Fusarium solani), альтернариозом (Alternaria panacis) и «черной пятнистостью» (Petriella asymmetrica) семена обрабатывались фундазолом и марганцем. C целью профилактики фузариоза сеянцев проводили опрыскивание бордосской жидкостью.

Для определения продукционных и морфофункциональных характеристик было отобрано 60 шестилетних растений. В период уборки определен вес корней, стеблей, листьев и плодов и морфологические признаки корней - длина и толщина главного корня, число боковых и придаточных отростков. Для 10 растений определено соотношение сырого и сухого веса органов, полученные усредненные коэфффициента использованы для определения сухого веса органов остальных растений выборки. Рассчитан процент распределения биомассы по органам растения по сухому весу - индексы корня листьев, стебля и плодов.

Результаты исследования и их обсуждение. Проведенное исследование обнаружило широкий диапазон варьирования по весу корней, морфологическим признакам корня, числу семян и распределению биомассы по органам растений. В таблице 1 приведены одномерные статистики (среднее, минимальное, максимальное значение и коэфффициент вариации). Продукционные характеристики варьировали в широких пределах, в наибольшей степени - длина главного корня (CV - $57 \%$ ), число придаточных корней (CV - 53 \%), число семян (CV - $48 \%$ ) и вес корня (CV - 43 \%). Сравнительный анализ показал, что полудикий приморский культиви- руемый женьшень по продукционным характеристикам в 1,5-2 раза уступает сортам Кореи. Средний вес корейских сортов женьшеня составляет 53-84 г, диаметр главного корня - 2,5$3 \mathrm{~cm}$ [2].

Распределение биомассы по органам отражает особенности донорно-акцепторных отношений растений. В процессе доместикации и селекции различных культур происходило увеличение одних органов, как правило, имеющих хозяйственную ценность, и уменьшение других. Так, у зерновых культур рост урожайности достигнут благодаря увеличению колоса или метелки и возрастанию Кхоз относительной доли зерна к соломе [7]. У женьшеня К хоз - это индекс корней, отражающий вес корня в процентах от веса растения. Ранее проведенные нами сравнительные исследования дикого и культивируемого в Приморье женьшеня показало, что у женьшеня наблюдается иная тенденция изменения Кхоз. Обнаружено, что в распределении биомассы по органам у плантационных растений доля плодов в ходе доместикации увеличилась, а корней - снизилась. Это привело к увеличению суммарной доли акцепторных органов (корни и плоды) на 12,3 \% и уменьшению вдвое доли донорных органов - листьев [8]. В анализируемой нами выборке обнаружено, что параметры структры биомассы - индексы плодов, листьев и стеблей также существенно варьируют. Более вариабелен индекс плодов (CV - $37 \%$ ), наиболее консервативен индекс корней (CV - $10 \%$ ). Наблюдаемая изменчивость в распределении биомассы по органам отражает разнообразие типов донорно-акцепторных отношений и морфотипов растений женьшеня на плантации. Около 30 \% растений выборки имеют индексы, близкие к дикому женьшеню. Полученные результаты свидетельствуют о присутствии на плантации растений, находящихся на разных этапах доместикации, - полудикие формы приморского происхождения и культивируемые разновидности корейского или китайского происхождения. 


\section{Продукционные и морфофрункциональные характеристики 6-летних растений культивируемого женьшеня}

\begin{tabular}{|l|c|c|c|c|}
\hline \multicolumn{1}{|c|}{ Признак } & Среднее & $\min$ & Max & CV, \% \\
& & & & \\
\hline Сырой вес корня, г & $41,2 \pm 2,3$ & 9,7 & 95,3 & 43 \\
\hline Длина главного корня, см & $4,4 \pm 0,3$ & 1,5 & 15.0 & 57 \\
\hline Диаметр главного корня, см & $2,1 \pm 0,06$ & 1,2 & 3,5 & 22 \\
\hline Количество боковых отростков, шт. & $4,0 \pm 0,2$ & 1,0 & 10,0 & 42 \\
\hline Количество придаточных отростков, шт. & $3,0 \pm 0,2$ & 0,0 & 7,0 & 53 \\
\hline Длина корневища, см & $1,5 \pm 0,07$ & 0,5 & 4,0 & 37 \\
\hline Число семян, шт. & $66,3 \pm 4,1$ & 13,0 & 146,0 & 48 \\
\hline Площадь листьев растения, см & $1012 \pm 40$ & 348 & 1971 & 33 \\
\hline Индекс корней, \% & $58,3 \pm 0,8$ & 45,5 & 72,6 & 11 \\
\hline Индекс листьев, \% & $11,6 \pm 0,4$ & 8,0 & 19,0 & 15 \\
\hline Индекс плодов, \% & $15,8 \pm 0,8$ & 5,3 & 28,5 & 37 \\
\hline Индекс стеблей, \% & $15,0 \pm 0,7$ & 8,4 & 27,9 & 32 \\
\hline
\end{tabular}

Примечание: статистические параметры рассчитаны для $\mathrm{n}=60$.

Анализ корреляционной взаимосвязи веса корня и морфоофункциональных характеристик растений выявил достаточно высокую положительную связь с толщиной главного корня $(\mathrm{r}=0,66 ; p<0,05 ; \mathrm{N}=60)$ (рис. $1, \mathrm{a})$, числом боковых корней $(r=0,45 ; p<0,05 ; N=60)$ и площадью листьев на растении $(r=0,61 ; p<0,05$; $\mathrm{N}=60)$ (рис. 1, б). Низкая положительная корреляция $(r=0,22, r=0,39 ; p<0,05 ; N=60)$ наблюдалась с признаками длина главного корня и корневища, число придаточных корней, индекс корня, индекс стебля. Высокая отрицательная корреляция веса корня наблюдалась с индексом листьев $(r=-0,65 ; p<0,05 ; N=60)$ (рис. 1, в). Обнаруженная нами корреляция веса корня и площади листьев согласуется с данными, полученными ранее другими авторами при исследовании 2-летних растений женьшеня. Высокая положительная корреляция веса корня и площади листьев женьшеня $(r=0,88)$ была получена в четырех вариантах, различающихся по уровню освещения (36; 20; 8; 2 \% от полного солнечного освещения) [9]. Снижение относительной доли листьев в весе наиболее продук- тивных растений анализируемой выборки хорошо понятно в свете эволюционных изменений морфотипа в процессе доместикации, который описан нами ранее. Сравнительные исследования дикого и культивируемого женьшеня показали, что изменение морфотипа культивируемого женьшеня происходит в направлении усиления «рудеральных» свойств, а именно увеличении доли генеративных органов (в данном случае числа плодов и семян) и уменьшении доли корней и листьев [8]. При этом происходят существенные изменения в структуре листьев культивируемого женьшеня: возрастает удельная поверхностная плотность листа, суммарная внутренняя ассимиляционная поверхность клеток и хлоропластов [8]. Эти структурные перестройки дают основание предполагать существенное повышение фотосинтетической активности листьев у культивируемого на плантации женьшеня. В частности было показано, что фотосинтез листьев женьшеня, культивируемого на искусственной плантации, был существенно выше, чем у горного женьшеня, выращенного под пологом леса [10]. 
a

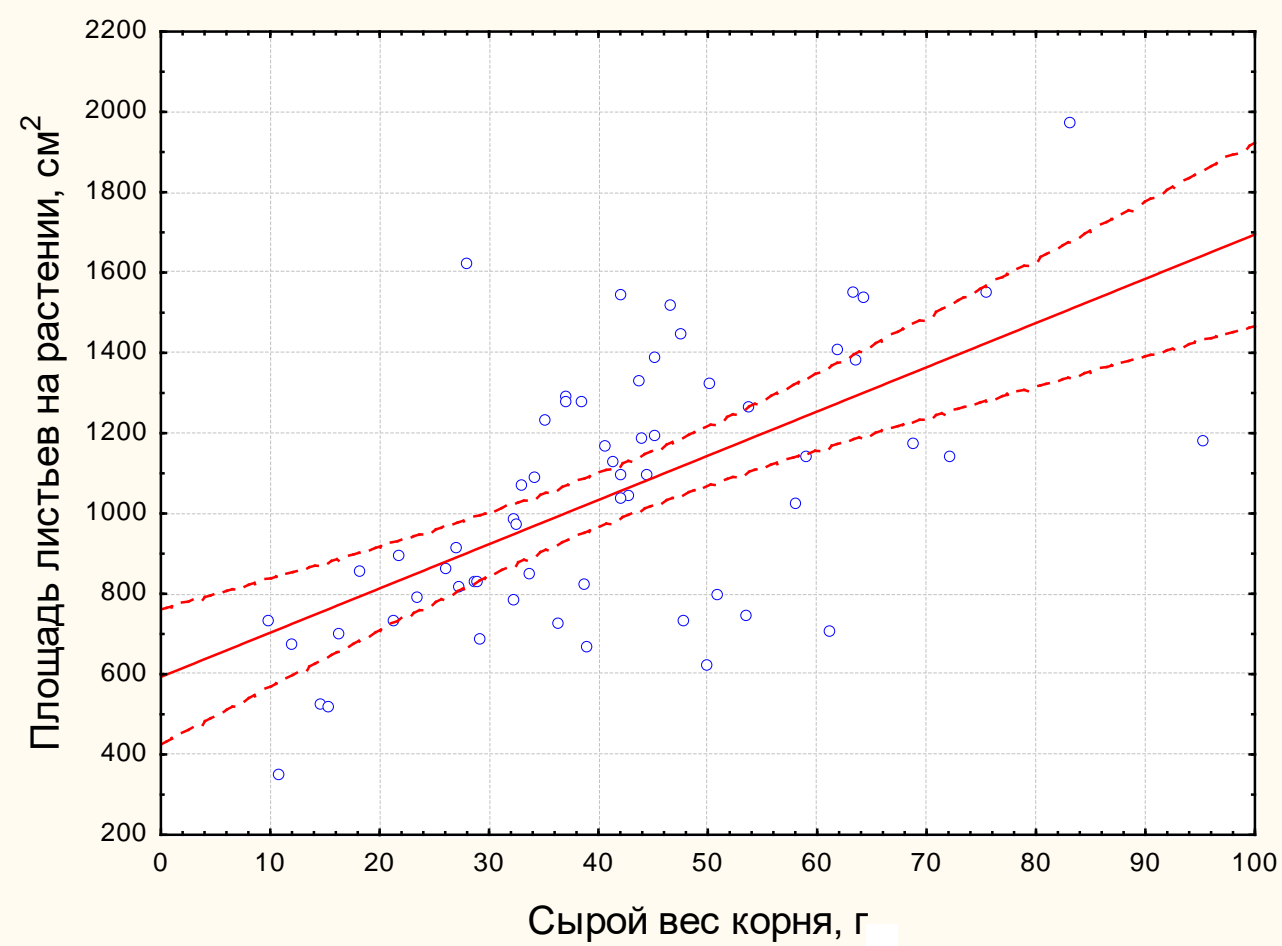

б

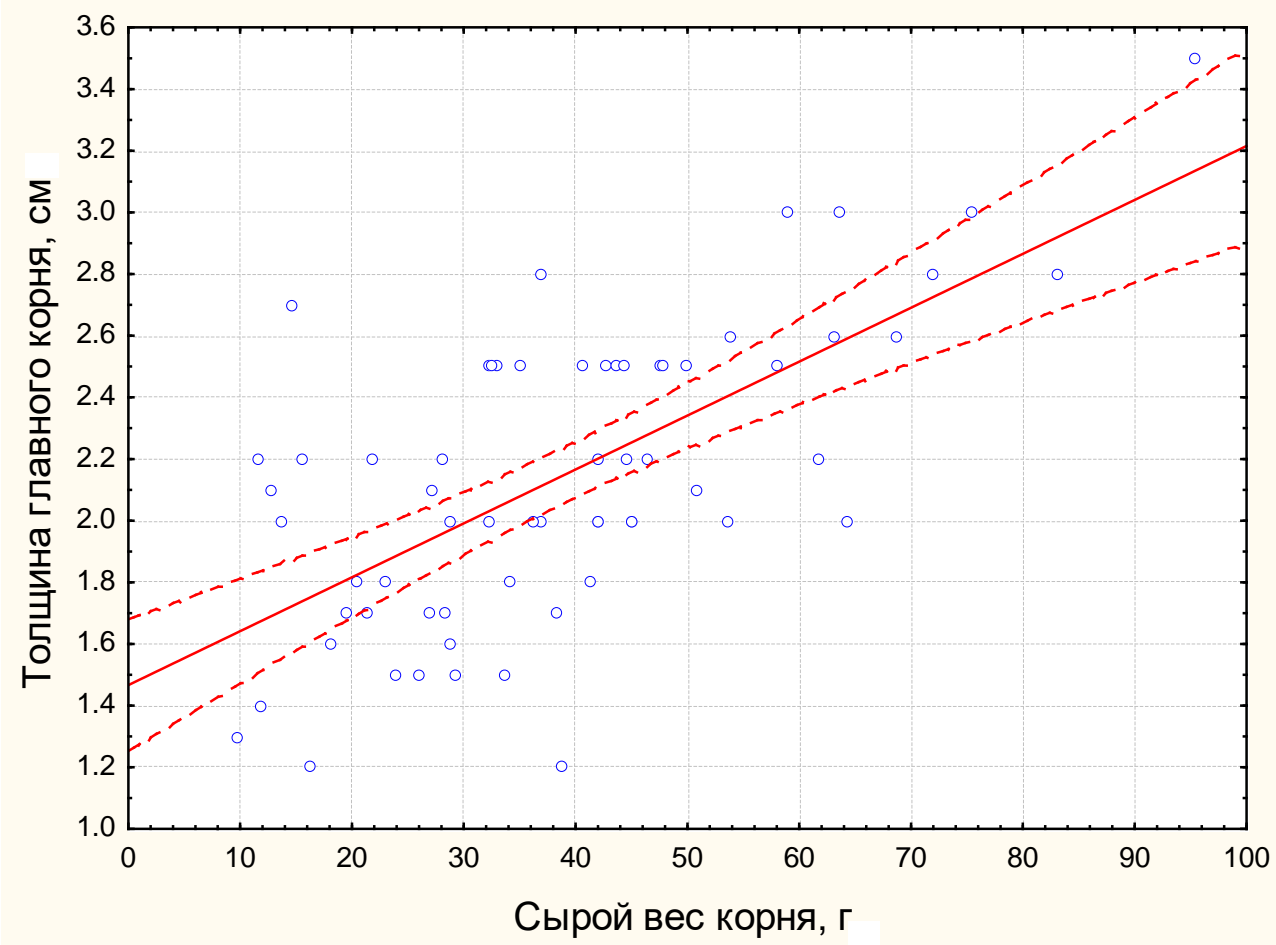

Взаимосвязь веса корня и морфоорункциональных характеристик растений культивируемого женьшеня 


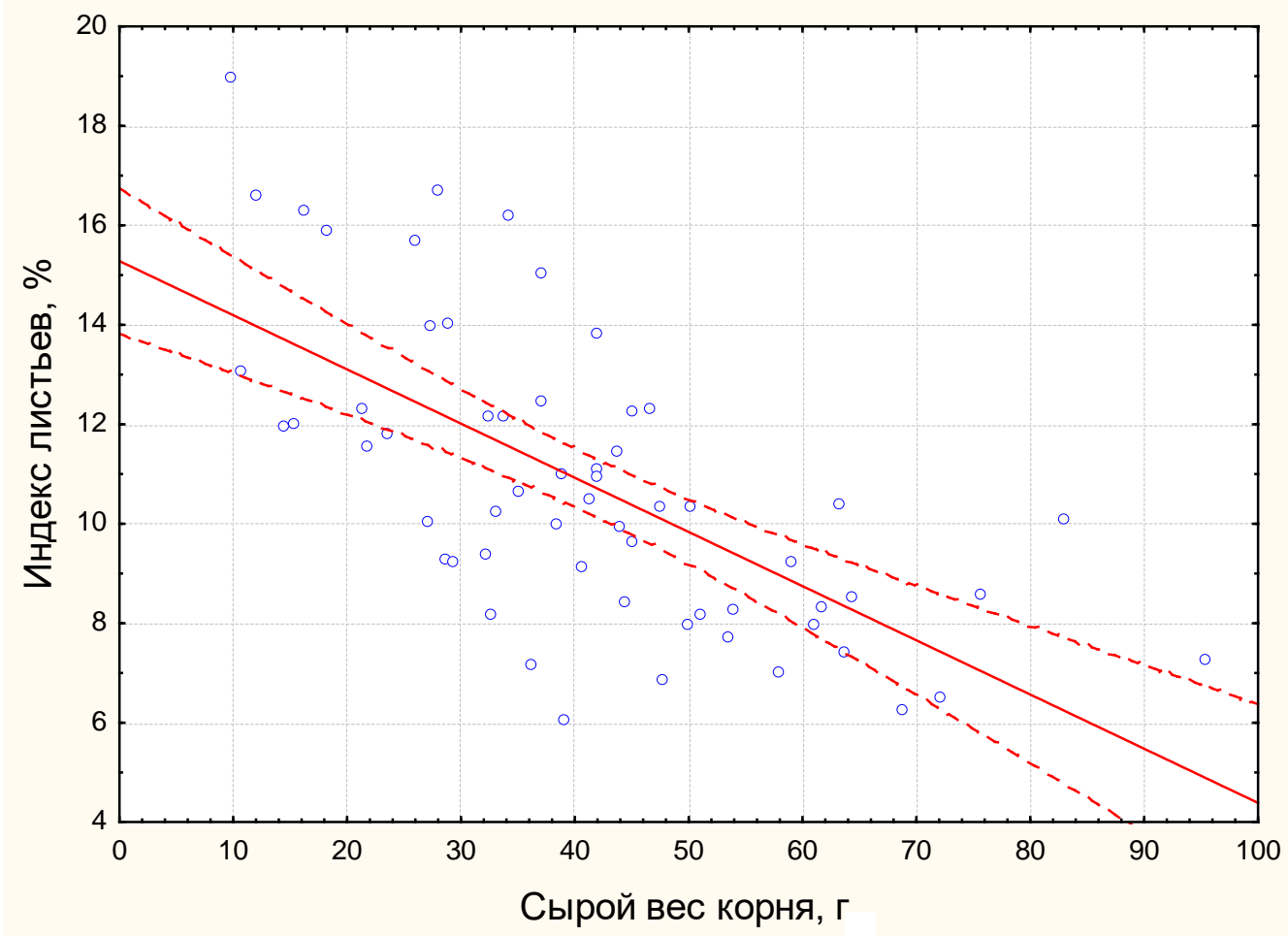

Окончание рис.

Выводы. Представленное на плантации разнообразие генотипов по продуктивности, морфотипу растений и морфологии корней свидетельствует о возможности проведения селекционных работ по созданию продуктивного приморского сорта женьшеня. Перспективными признаками для отбора, по результатам нашего исследования, могут быть предложены толщина главного корня, число боковых корней и площадь листьев растения.

\section{Литература}

1. An introduction to Korean ginseng: The elixir of life // Lee F.C. et al. Front Cover. Korea ginseng and tobacco institute. - 1983. - $119 \mathrm{c}$.

2. Lee J.H. et al. Characteristics of Korean ginseng varieties of Gumpoong, Sunun, Sunpoong, Sunone, Cheongsun, and Sunhyang // Journal of ginseng research. 2015. - T. 39, № 2. - C. 94-104.

3. Kim Y.C. et al. 'Kowon', a New Korean Ginseng Cultivars with High Yield and Alternaria Blight Resistance // Korean journal of Horticul- tural s Science and technology. - 2017. T. 35, № 4. - C. 499-509.

4. Быков О.Д., Зеленский М.И. О возможности селекционного улучшения фотосинтетических признаков сельскохозяйственных растений // Физиология фотосинтеза. М.: Наука, 1982. - С. 294-309 .

5. Мальшев А.А. Женьшень. - М.: Агропромиздат, 1991. - 144 c.

6. Зражва Б.А. и др. Культура женьшеня: рекомендации по технологии выращивания / под общ. ред. А.И. Живчикова. - Владивосток: Изд-во ДВГУ, 1992. - 80 с.

7. Ничипорович А.А. Фотосинтез и теория получения высоких урожаев // Тимирязевские чтения. - М.: Изд-во АН СССР. - 1956. T. 15. - C. 93.

8. Бурундукова О.Л. и др. Морфофуунциональные основы смены стратегии адаптации женьшеня (Panax ginseng C.A. Meyer) при окультуривании // Доклады Академии наук. - 2012. - Т. 446, № 5. - C. 594-597.

9. Parmenter G., Littlejohn R. Effect of shade on growth and photosynthesis of Panax ginseng // New Zealand Journal of Crop and Horticultural Science. - 2000. - T. 28, № 4. - C. 255-269. 
10. Choi Y.E., Kim Y.S., Yi M.J. et al. Physiological and chemical characteristics of field-and mountain-cultivated ginseng roots // Journal of Plant Biology. - 2007. - T. 50, № 2. - C. 198205.

\section{Literatura}

1. An introduction to Korean ginseng: The elixir of life // Lee F.C. et al. Front Cover. Korea ginseng and tobacco institute. $-1983 .-119 \mathrm{c}$.

2. Lee J.H. et al. Characteristics of Korean ginseng varieties of Gumpoong, Sunun, Sunpoong, Sunone, Cheongsun, and Sunhyang // Journal of ginseng research. 2015. - T. 39, № 2. - S. 94-104.

3. Kim Y.C. et al. 'Kowon', a New Korean Ginseng Cultivars with High Yield and Alternaria Blight Resistance // Korean journal of Horticultural s Science and technology. - 2017. T. 35, № 4. - S. 499-509.

4. Bykov O.D., Zelenskij M.I. O vozmozhnosti selekcionnogo uluchsheniya fotosinteticheskih priznakov sel'skohozyajstvennyh rastenij /I Fiziologiya fotosinteza. - M.: Nauka, 1982. S. 294-309 .
5. Malyshev A.A. ZHen'shen'. - $\mathrm{M}$ : Agropromizdat, 1991. - $144 \mathrm{~s}$.

6. Zrazhva B.A. i dr. Kul'tura zhen'shenya: rekomendacii po tekhnologii vyrashchivaniya / pod obshch. red. A.I. ZHivchikova. - Vladivostok: Izd-vo DVGU, 1992. - $80 \mathrm{~s}$.

7. Nichiporovich A.A. Fotosintez i teoriya polucheniya vysokih urozhaev // Timiryazevskie chteniya. - M.: Izd-vo AN SSSR. 1956. - T. 15. - S. 93.

8. Burundukova O.L. i dr. Morfofunkcional'nye osnovy smeny strategii adaptacii zhen'shenya (Panax ginseng C.A. Meyer) pri okul'turivanii // Doklady Akademii nauk. - 2012. - T. 446, № 5. - S. 594-597.

9. Parmenter G., Littlejohn R. Effect of shade on growth and photosynthesis of Panax ginseng /I New Zealand Journal of Crop and Horticultural Science. - 2000. - T. 28, № 4. - S. 255-269.

10. Choi Y.E., Kim Y.S., Yi M.J. et al. Physiological and chemical characteristics of field-and mountain-cultivated ginseng roots // Journal of Plant Biology. - 2007. - T. 50, № 2. - S. 198205. 